\title{
Research on Utilization of Academic Research Achievements in Public Opinion Guidance
}

\author{
Mei $\mathrm{Xie}^{1, \mathrm{a}}$ and Luona $\mathrm{Su}^{2, \mathrm{~b}}$ \\ ${ }^{1}$ School of Political Science and Public Administration, University of Electronic Science \\ ${ }^{2}$ Technology of China, Chengdu, Sichuan province, CHINA \\ a13908033701@163.com, b405287640@qq.com
}

Keywords: academic research achievements, pubic opinion guidance, the public

\begin{abstract}
Many authoritative academic papers, research reports and other scientific research achievements are published in China every year. However, they are put in databases and periodicals all the time after publishing and not effectively utilized by the public indeed.Academic achievements are always in the form of papers or reports and people will not learn correctly through consulting academic research achievements, leading general disorder of public opinion. Through theoretical analysis of academic research and public opinion, the dilemma that public opinion is guided with academic research achievements at present is proposed in the Thesis and conclusion is drawn about how to promote academic research achievements to truly "step to" social primary level in terms of the public, governments, experts and scholars.
\end{abstract}

\section{Overview of academic research achievements and social public opinion}

Academic research has been conducted by scholars from ancient times and is used to help us solve various problems in society and correctly guide social public opinion. Its importance is self-evident and it is the basis of analysis to understand the concept of academic research and public opinion.

\subsection{Concept of academic research}

The word "academic" has been existing for a long time in China. The definition of academic in Cihai is relatively specialized and systematic knowledge. In modern sense, Chinese scholars have not applied it until the end of the $19^{\text {th }}$ century and the beginning of $20^{\text {th }}$ century instead of applying "learning" and "expertise" separately. Afterwards, Chinese scholars gradually combine "learning" and "expertise". It can be understood that academic is to explore a correct path to the future from previously accumulated experience and theoretical knowledge. Nowadays, rapid development of science and technology makes academic research develop towards scientific, normative, systematic and disciplined cross-research path.Academic research achievements include research reports, papers, etc. Academic research achievements and their expression forms can be further clarified only through truly understanding the connotation of academic.

\subsection{Current situation for publishing of academic research achievements in China}

In recent years, the quantity of academic research achievements in China has continuously increased. In terms of 2014, 1,766,300 scientific papers were published in SCI database in the world, increasing by 3.3\% than 2013. There are 263,500 Chinese scientific papers included and Chinese scientific papers rank the second in the world for six successive years, accounting for $14.9 \%$ in global share. The share in 2014 increased by 1.4\%. The top 5 countries in the world are respectively America, Chinese, Germany, Britain and Japan. There are totally 235,100 papers with China as the first author, accounting for $13.3 \%$ in the world, increasing by $15.2 \%$ than last year.

\subsection{Research field and core opinions of Chinese academic research achievements}

Top ten disciplines in terms of publishing of international conference papers in China in 2014 are 
respectively electronics, material science, communication and automatic control, computer technology, energy science and technology, physics, mechanical technology, civil construction, clinical medicine, environmental science and chemistry, physics. In addition, papers published in international social and scientific journals involve over 40 disciplines and the top six disciplines are respectively economics, management, education, languages, library and information science, sociology.As for all disciplines, core opinions of academic research achievements have their own advantages.Understanding and learning core opinions of academic research achievements of all disciplines is effective approach for the public to keep independent thinking in the face of hotspot events.

\subsection{Overview of social public opinion}

Events with development closely related to people's livelihood will mostly give rise to people's mental and behavior reaction. When our reactions are suitable for objective conditions, public opinion will be formed, or rumors will be formed. Public opinions mainly reflect people's emotion, viewpoints, interest demand, etc. and are roughly consistent speech and behavior intention of the public for social events and problems arising at present. Therefore, public opinions need guidance and concerted efforts of multiple subjects,Public opinion guidance is characterized with interaction, guidance, artistry and regulation.

\subsection{Current situation of academic research achievements and public reading}

It is well known that periodical is an important carrier of academic research achievements and important communication media of theoretical knowledge. However, periodicals are not favored by the public. In the morning of April 18, 2017, the Chinese Academy of Press and Publication issued the $14^{\text {th }}$ survey report for national reading throughout the country. The report indicates that comprehensive reading rate of national periodicals for adults in the country in 2016 is 26.3\%, decreasing by $8.3 \%$ than $34.6 \%$ in 2015 . At the same time, the reading quantity of per capita periodicals of Chinese citizens in 2016 is 3.44 periodicals (number) and media contact duration of periodicals is only $6.61 \%$. The reading rate and media contact of periodicals are far below books, newspapers, mobile phones, ranking the bottom. Survey data show that the contact rate for mobile reading of national adult citizens in 2016 is up to $66.1 \%$.. It can be seen that academic research achievements are not truly incorporated into the reading field of common people.

\subsection{Correct guidance of social public opinion with academic research achievements}

Academic research achievements provide new knowledge insights for everyone in the society and promote solution of social issues. The purpose of academic research is to solve certain problem, including problems raised theoretically or practically by researchers. However, when we encounter these social events, most people fail to read and learn these academic research achievements instead of being guided by some box news and journalists. In the future, these livelihood fields are still peak stages for development of public opinion. It requires learning core opinions of subject areas involved in such type of events, for these opinions are formed through endless investigation and learning. Therefore, they are of scientific value and realistic guidance significance.

\section{Reflection on public opinion guidance value of academic research achievements}

Preliminary social public opinions of many hotspot events are inconsistent with facts and public opinions are always "guided" by media. In the face of various social hotspots, crisis and sensitive events, we should consult academic research achievements to reasonably treat these social hotspot events, but these achievements are not effectively utilized. Then these scientific research achievements lose their publishing significances. The author holds that there are many reasons behind it. 


\subsection{Common people's lack of consulting awareness and easiness to follow blindly}

When audiences contact social events, they do not have the habit to analyze problems with academic research achievements instead of seeing issues following majority public opinions or public opinions consistent with their own viewpoints and lacking media literacy and scientific literacy. Media literacy of netizens is a new concept. Specifically, it refers to that whether one can correctly and effectively select information in the face of massive information in the Internet, effectively utilize network resources, set up proper motivation to use network resources, develop effective resource utilization method and correct attitude, improve utilization degree and criticism ability of network resources. Some audiences are influenced by "opinion leaders" around and know these events through "secondary communication", lacking independent judgment, and intensifying dominated public opinion. Some people even conceal their own viewpoints and follow dominated opinions to obtain recognition and become "spiral of silence".

\subsection{The government's negative attitude at the time of handling social public opinion}

As the information source with high credibility, governments lack guidance on public opinions and awareness to effectively utilize academic achievements. In the network era, no importance is attached to seemingly unimpressive social events and public opinions develop freely. Governments do not stand out to dredge public opinions effectively until serious consequence is caused, such as endlessly emerging campus bully events, network fraud cases this year. Governments hold attitudes of "silence is gold" towards many social problems and make public opinions develop beyond control.

\subsection{Lack of generally accepted forms in terms of current academic research achievements}

In terms of communication scope, the communication scope of academic research achievements as a seemingly "high-end, classy and high-grade" is mostly kept in people with high education background (bachelor degree and above) and social primary level and the masses lacking education in the last generation are basically hard to read academic papers. In terms of communication subject, many academic research achievements are written obscurely and there are many terms, which are abstract and difficult to understand. It is hard to cater to reading flavor of the public. Therefore, people lack patience to read off a high-level paper in busy daily life. Furthermore, papers only focus on model instead of thought.

\section{How to correctly guide social public opinions with academic research achievements}

It is not easy to truly introduce academic research achievements social primary level and attention shall be paid to the public, administrative subject, experts and scholars.

\subsection{Cultivate common people's awareness to consult academic achievements}

Cultivate and improve scientific literacy of the public. In the future, more efforts shall be made to energetically develop scientific promotion undertakings, material civilization and spiritual civilization construction of Chinese society. Drastically boosting scientific promotion undertakings can not only improve scientific quality of the whole people, but also cultivate scientific literacy and scientific interest of adolescent students. At the same time, threshold access of scientific promotion shall be reduced and free library, museum and other reading places shall be built energetically. In the new media era, the public shall be called on to learn data retrieval, paper consulting with computers, mobile phones and other effective tools, abandon former prejudices for "academic" and truly make academic research achievements step to the primary level.

\subsection{Build government information publicity and promote scientific promotion}

As for information publicity and query, the government shall actively cooperate with the public; at the onset of outburst of social hotspot event, the government shall carry out one-stop guidance 
and supervise comprehensively. In the new media era, the government shall build official government website and purify development environment of public opinions in the Internet. After outburst of network events, the government shall promptly release effective information through Internet and actively guide social public opinions. In addition, the government shall develop existing network spokesman system and promptly reply post of the government about information to eliminate doubts of the public. At the same time, scientific promotion shall be energetically boosted and excellent academic research achievements shall be promoted to the public for learning. National reading, academic periodical donation and other activities shall be held regularly and even a database belonging to the public can be built for consulting.

\subsection{Improve expression forms of academic research achievements}

Change academic research achievements to "general reading materials". The first step to make academy step to the public is to abandon the concept that "general reading materials are unpresentable”. Some scholars hold that straightaway reading materials are always vulgar and works with obscure style show that the author has profound thinking or contents are authoritative, full and accurate. This practice undoubtedly adds a "profound" appearance to academy and separates academy from primary-level people. Such pro forma "red-tapism" is misleading. Studying for application is a constant truth. We must understand that the true purpose of academic research is to solve problems. Regardless of academic realm, it shall be reflected to real life to find its true value. We need to bring academic research out of high "ivory tower" and bring it to the most civilian "soil land" and come back to earth. Then we can change our academic achievements to general reading materials benefiting human and bring value to more people.

\section{References}

[1] Dictionary of Philosophy. Marxist Philosophy Volume [Z].Shanghai: Shanghai Lexicographical Publishing House, 1990. 506.

[2] Report of Online Public Opinions for Social Hotspot Events in 2016. Xinhuanet.2017.1.4

[3] Feng Zirong. Media Literacy of Audiences in General Information Era [J]. ModernAudio-VideoArts,2007(5).

[4] Yang Kunqi. Discussion on Cultivation of Media Literacy in Network Communication Era[J].Caizhi,2010(15).

[5] Zhang Zizhong. Avoiding Information Variation: Directly Facing the Public[J]. People Forum, 2009(11):41.

[6] Cui Kai. How to Make Academy Step to the Public[J]. Academic China..2016.10.31 